need not the rest cure, but education, occupation and gradually increased exercise, mental and physical. The business man, on constant strain, who after many years, breaks down, is a distinct type, as opposed to a nervous individual, always dominated by an idea, who receives a shock and from the effect of that develops the neurasthenic state. These two classes are certainly distinct and they should have different treatment.

Dr. WM. G. SpILlER-Neurasthenia may sometimes prove fatal; I have several times seen patients at the point of danger; I think the explanation of nerve exhaustion is applicable to such a condition and I would like to see the nervous system of such a patient examined by the method of Nissl. Within the nerve cells would be found, I think, some change of the chromophilic elements.

Dr. Moyer-My conception of neurasthenia is that of nerve fatigue; if that is not present the condition is not true neurasthenia.

Dr. JONES-The base of neurasthenia is cell-fatigue, and it makes no difference whether in a working man or a society woman. If the nerve cell is in a fairly stable condition, the patient has the neurasthenia described by Dr. Dercum; if he has an unstable nervous system, he has the form described by Dr. Patrick. The real question is as to the stability or instability of the nerve cell.

The complete exhaustion of a center seems to me rather com mon, although it has been looked upon, perhaps, as other than neurasthenic; but it can be very reasonably explained by the theory of absolute cell exhaustion, the cell being restored under certain conditions and the motor function returning

Dr. LODER-There are two forms of neurasthenia as widely dissociated as any two diseases of the nervous system. I have yet to see one case of neurasthenia that did not show a very profound hereditary impress. I believe if we put the chromophilic gland under the microscope we will be able to differentiate these cases.

Dr. A ugustus A. Eshner-Neurasthenia has varied causes. The sueceptibility of the individual nerve cell must vary in the same individual under different circumstances. So, too, the designation of "cell tire" must be accepted as exceedingly vague. Perhaps we do not improve upon such a designation if we assume that from excessive or deranged function there result certain metabolic changes, certain alterations in cellular nutrition, which is the essential basis of these varying kind of neurasthenia or of neurasthenia depending upon a variety of causes. This intoxication, in consequence of the obverse intracellular innutrition, may produce such alterations in neuronic, in ultimate cellular elements, as to give rise to these symptoms which we designate neurasthenia.

While many cases are susceptible to a general line of treat. ment, the basis of which consists in the re-establishment of internal equilibrium, and into which enter especially the elements of rest, over-feeding and the removal of general psychic disturbances, still the results of therapeutics seem to sustain the view that neurasthenia is dependent upon varied intoxications of the ultimate cellular elements, sometimes cerebral, sometimes spinal, sometimes cerebro-spinal.

Dr. W. J. Herdman - For ten years I have been studying neurasthenics with regard to their temperature. I have found it invariably abnormal; almost uniformly raised, but occasion ally lowered. As elevations of temperature are known to cause deviations from the normal state of metabolism, this may become, finally, an etiologic factor. Fear is present in some cases as one of the sequelæe of neurasthenia. One patient who had recovered from this disease, suffered from a horror of elevation. It was impossible to make him go higher than the second story of a house. When in elevators it was necessary to restrain his mad impulse to try to jump out.

Dr. Cleaves-I have found that this sequel of fear has been relieved by Franklinization.

Dr. Dercem - Neurasthenia is a fatigue neurosis, and all that is not a fatigue neurosis is something else. Possibly it may be an obscure case of interstitial nephritis, in which it is necessary to make repeated eearch in the urine to find the proof ; and you have other cases of pseudo-neurasthenia; the mere fact that they reveal some of the symptoms, though not the true syndrome, does not make them neurasthenia. There are certain persons who are born with a certain predisposition, and under certain strains become neurasthenic; these are the patients who become insane if the strain is prolonged, and who may become paranoiacs in later life.

It is possible to have neurasthenia from physical exertion. A fatal case of neurasthenia was of a college athlete who had overtrained. He broke down and became profoundly neuras thenic. It was a purely physical case; he did not study hard at college, but exercised very severely. He became a terminal neurasthenic, and grew to be like an old man. I could not get an autopsy, but as far as I could tell there was no disease of any one organ.

I have observed slight variations of temperature. It some. times rises as a result of animal fatigue, and perhaps we have here a hint as to the temperature of neurasthenics being slightly above normal. I believe that fears are a secondary outgrowth. They belong to the secondary symptoms, and I suspect that in those cases in which they are so tenacious, and become a part of the individual, there is some neuropathic train

With respect to the pathology of neurasthenia, it seems to me very unfortunate that we have not paid more attention to the remarkable results of Hodge's experiments on the fatigue of nerve cells. Hodge first studied bees from the same hive. Several were penned in the hive; others were on their flight all day carrying honey. He killed one of each at the same hour, took the same ganglion from each and compared them. He always found that the cell from the bee that worked was smaller, and there was a tendency to vacuolation of the gen eral cell contents, while the nucleus stained differently. He tried similar experiments with pigeons, and the cells showed the same changes. He excised the posterior spinal ganglia in cats. To exclude all possible sources of error he would take the same ganglion on the two sides, exciting one by the electric current. There were marked changes in cell substance.

The urine is never normal, and there is always some derangement as regards the uric acid. The excessive nuclear waste would account for the increase of uric acid in these cases.

The protonucleins stimulate these cases, but the amount of good has never been enough to make it an essential part of the treatment. It is probable that such benefit as has been obtained from the Brown-Séquard injections is due to the fact that the elixir contains a very large amount of the protonuclein in its active form.

I have come to the conclusion that strychnia increases the nervousness. I use it only occasionally and in small doses.

Generalized forms of fear get well without any trouble: specialized forms in my experience do not, except sometimes spontaneously. In some way perhaps the tissue metabolism is changed by the Franklinization.

Dr. G. BETTON MASSEY - If neurasthenia is caused by fatigue, you would find it in the Adams expressmen, the trunk lifters and carriers. Nerve cells change under the expenditure of energy, but it is a mistake to attribute those changes as an exactly similar condition in neurasthenia. It seems to me that the fatigue neurosis is a relative one.

\section{MELANCHOLIA AND ITS TREATMENT.}

Presented to the Section on Neurology and Medical Jurisprudence, at the Forty-eighth Annual Meeting of the American Medical Association, at Philadelphia, Pa., June 1-4, 1997. BY W. S. WATSON, M.D.

RIVERYIEW SANITARIUM, FISHKILL-ON·HUDSON, N. Y

The symptoms are despondency, sorrow, fear and despair in degree beyond the natural emotions. Anxiety, grief and fear are peculiar to the normal mind and it is only when they exist to such a degree as to be beyond the power of reason and not in harmony with the laws of logic that we may justly style them morbid or call them delusions. Melancholia, as a rule, does not come on abruptly; on the contrary it is a condition of slow growth, with bodily symptoms of so trivial a nature as to scarcely attract attention; notwithstanding, we believe it is more frequently due to physical conditions than otherwise. Melancholia does not necessarily follow neurasthenia. Observation of cases coming under our treatment strongly incline us to the belief that we should look for toxic causes, autc-toxic substances, poisons created within the body, which, step by step, exert a destructive influence over cell formation, while degenerative changes and insanity follow later. We do not pretend that there are no other than physical causes for mental diseases, or that insanity may not be the product of two or more generations or the outgrowth of arrested evolution, powers destroyed or undergoing changes retro. grading; we do know that the various mental diseases 
imply pathologic implications of the brain; that the brain is touched, in one way or another, and is no more normal in its functions; that its vascular apparatus, its cells, ganglia, meninges or other bearings are involved directly or reflexly. Admitting as we do that the brain is involved in insanity, that it gives expression, we do not concede that the brain is alone or always primarily at fault in mental disturbances, but rather that the mentality of the individual and all the conditions, both physical and psychical, that make up the impressions and expressions are, in fact, the phenomena of insanity.

The nervous symptoms and mental manifestations arising primarily from auto-intoxication due to retained fecal or urinary constituents do not directly produce the nerve reaction; in other words, nerve reaction can not produce infection, except by making infection possible by weakening the defense which a healthy organism naturally offers to the invasion of microbes, or by modifying nutrition so as to develop a medium favorable to low forms of organisms; a weakened or a disturbed nervous system produces defective nutrition, which in turn opens the inroads of infection. Not only are the inroads opened by disturbed nutrition and nerve action, but there also follows an interference in the distribution of the force, which liberates certain substances elaborated by the different organisms by modifying, augmenting or diminishing the normal proportions; hence myxedema is dependent upon perversion of the functions of the thyroids, as will be shown in our enumeration of cases in the course of this paper.

It may be truly said that within the human organism there exists a constant tendency to toxemia from accumulations, and that intoxication can only be avoided by a perfect performance of functional integrity. In melancholia it is the slight exhibitions or manifestations that are of prime importance. The early recognition of the initial symptoms affords an opportunity to ward off an attack that may later lead to insanity. In the melancholic we meet with the self-conscious, or with a lack of buoyancy and selfreliance; morbid fears are more or less marked, so much so as to be justly called delusions, out of which the individual can not be reasoned. Yet there may be no hallucinations whatever. $\mathrm{He}$ is aware of his defective judgment and anxious to rid himself of all, yet try as he may, the tendency is to recall, to revert to that which is troubling him whether there be any real foundation or not. There seems to be a lack of power to fix the mind upon anything else; strength of reasoning is gone, a dislike for association with others, a strong aversion to meet those they otherwise know to be their friends is fixed within them; with many there is a periodic aversion to those most dear to them. Instead of the usual marks of affection there are marked explosions of dislike and hatred, jealousy and suspicion. Jealous without the least provocation, jealous of everybody. If it be a married lady, she criticises every move of her husband, suspects every one of her own sex, imagines that all women want her husband, that every little courtesy shown to other women by her husband is meant as a slight to her. Such feelings dominate her entire nature, and her suf. ferings in consequence are indescribable; jealousy is a marked symptom in the melancholic, and when possible to trace melancholia to its actual source, a very large per cent. originates in domestic unhappiness, disappointed love and incompatibility. In the manage- ment of such cases much depends upon the environ. ments: separation from all that has surrounded the sufferer during the period of development. Nothing so encourages or feeds the morbid feelings or fires up the outbursts of hatred and dislike as being in the presence of the object of that jealousy, or other unnatural feeling. While it is well and proper to cheer and sustain and soothe our patient by words and acts, it is equally necessary to check and reprove by denying certain indulgences. Separation from relations is ofttimes a cure in itself. The sympathizing acts of relatives tend to increase the morbid imagination already in the mind of the melancholic. We can no better express our reasons for believing it all-important to remove the melancholic from his home than to quote the language of Dr. Pinel. It is, he says, "generally so sweet to an invalid to be in the bosom of his family, there to receive the care and consolation of a tender and compassionate affection, that it is with pain I announce a sad truth, one established by repeated experience; namely, the absolute necessity for confiding the mentally disturbed to the hands of strangers and isolating them from their relatives." It is well to bear in mind that not infrequently family differences and domestic discord are closely connected with the origin of the mental disorder. The successful management of the melancholic not only requires separation from friends and home but the help of those trained to assist-a physician and nurse. To the trained or skilled nurse many of the details of treatment are dependent. A properly selected atten. dant, one possessing a large amount of patience and endurance, full of humanity, intelligent, zealous in his endeavors to carry out the directions of the phy. sician, is invaluable, and no melancholic case has a reasonable chance of recovery without such constant help and attention as can only be afforded them through proper attendance. Attendants have many privations and discomforts to endure in addition to the responsibility accompanying such a position; and if they be conscientious and diligent, deserve words of commendation and appreciation from those in authority. It is the attendant that hourly hears the complaints, and he needs have a ready an swer at all times for the poor melancholic, to offer cheer and to lead the perverted mind into brighter fields. Much, indeed, depends upon the tact of the attendant in imparting hope and in leading the patient to believe his disease is a physical one or dependent upon physical causes. A melancholic patient should never be allowed to understand that his disease is one of the mind. Their greatest fear is that they will become insane. A good attendant will never allow an intimation of mental trouble to be made in the hearing of his patient.

Treatment.-Medicinal therapeutics do not offer anything very satisfactory, although much can and must be done to ameliorate the suffering, imaginary and otherwise. Since constipation is an accompaniment and is either due to natural sluggishness or want of attention, we would commence by giving a brisk cal. omel purge to unload the accumulations and possible cause of auto-intoxication. Frequently the patient brightens up at once and remains so if the condition of the bowels is watched carefully; but if they are allowed to become inactive there will be almost invariably a relapse. So, in regard to the urinary secretions, careful attention is important. A kidney lesion may and often is an important factor in the accumulation of toxic products. The habit 
of defecating at a stated time should be encouraged and required. Antiseptics, as salol, naphthalin, etc., are of value and can be used to some advantage for their local antisepsis on the intestinal tract. Insomnia is a feature of great importance and one controlled with difficulty in many cases. If the true cause of worry can be ascertained and removed an important point is gained; if the circulation is slow and extremities cold, static electricity will do more than all else in procuring sleep, by improving the circulation; if the skin is dry and husky, with coldness of the extremities, Turkish baths with the accompanying rubbing and manipulations are indicated; if such means together with judicious counsel by the physician giving moral support in words do not overcome the sleeplessness then drugs will have to be given. Kola, bromids and chloral are about the safest and best. Codeia we use with considerable success in doses ranging from 0.016 to $0.1 \mathrm{gram}$, it pro. duces rest and sleep by its inhibitory power over nerve irritability. Hyoscin used hypodermically is of all drugs the one that soothes best and lasts longest. We have never seen an untoward symptom follow its use. It must be remembered that hyoscin is one of our most powerful relaxants, a cerebral sedative and hypnotic; especially indicated in melancholic frenzy and motor excitement.

Systematic exercise, occupying the entire time, is of great importance; giving exercise consistent with the patient's physical condition is very important and tends to divert the mind. Walking, riding, playing games, rowing, chest-weight exercise, dumb bells, etc., are excellent. Thyroid feeding reaches some cases. We have been using thyroid almost since it was first suggested or could be obtained. It has, in our experience, proved curative in one instance, which we shall give. At the present time there are diversified views as to its action. It is our opinion that it will be found of value only in the degenerate conditions and myxedematous cases with possible atrophy of the thyroids. There must, at least, be defective functional activity of the thyroids, since it would seem that they secrete something that acts as an antitoxin and in that way counteracts the tendency to intoxication and consequent mental impairment, or there is in the blood of the mentally disturbed a toxin that the normal thyroid is incapable of antagonizing; hence the necessity for supplying thyroid artificially. It is, we think, pretty conclusive that the thyroids supply to the circulation a substance that is required to maintain its proper composition to sustain brain nutrition, or their secretion prevents auto-intoxication by destroying the poisonous products of metabolism. The results of thyroid treatment at Riverview Sanitarium warrants, we believe, the conclusion that thyroid can not be looked upon as a remedy for mental disease or that it may be generally used in all cases; on the contrary, it is applicable in cretinism and mental degeneracy of insanity. Myxedema is comparatively a new disease, attention having been called to it only about twenty-six years ago, and is primarily a bodily disease. Mental impairment follows after a time. We had great hopes after reading the report of Dr. T. S. Clauston, medical superintendent of the Royal Edinburgh Asylum, in 1892, on the use of thyroid, that a means had been discovered that would reach a large per cent. of insanity cases. Later reports together with our own experience even in mild mental cases, show that our hopes were placed too high. It is, however, certain that thyroid extract is a therapeutic agent of value in selected cases and that cell changes are affected by it in a remarkable manner; the quickened circulation undoubtedly increases metabolism.

Case 1.--Miss A., age 28 years, admitted March 28, 1896; weight 185 pounds, German descent, American born; showed mental disturbance three years previous but seemed to recover, relapsed May, 1896; when admitted was at times erratic, at others stuporous; slow in decision; strong erotic feelings; myxedematous appearance. 'Thyroid was given in 0.32 gram doses, t. i. d., for a period of ten days; patient's circulation or pulse rate was increased with complaint of fulpess in the head, palpitation, fibrillary twitching of hands, crawling sensations with increased erotic feeling. It was thought best to discontinue the remedy, as there was a general aggravation of the symptoms.

Case 2.-Mrs. R., age 46 years, had been an inmate of an asylum eighteen years previous, during her puerperal state, since which time had remained well. When admitted showed decided nervous symptoms, insomnia, meaningless laughter and extreme restlessness with outbursts of religious excitement. Thyroid was given in 0.32 gram doses the first three days and increased to 0.65 gram, t. i. d., with steady increase of insane symptoms; at the end of third week it was necessary to remove her to an insane asylum.

Case 3.-Miss P., age 33 years; admitted Oct. 12, 1896; had been ill over a year; whole disposition had changed from an active worker and unassuming maiden lady to the belief that she belonged to some man or ought to, showing marked erotism in various ways, whole mind seemed to be upon man, how this or that one could save her, etc. Thyroid was given in increasing doses, beginning with 0.32 gram, t. i. d., believing the extract might be indicated from the degenerate tendency of the mind; after the doses had been increased to 1 gram, t. i. d.. the erotism had so increased as to make it necessary to watch the patient every moment, lest she, in her uncontrollable condition, would make a show of herself; every expression and movement as well as words showed intense sexual excitement; the thyroid was discontinued. Hyoscin and codeia was given in moderate doses and in five days the undue sexual feeling was gone. The patient remained under our observation and treatment for a period of three months, when she had recovered to such an extent as to be sent to ber friends cured. Case 4.--Miss A., again on thyroid, Dec. 18, 1896 . She is of a neuropathic family, the history is, that an older brother had Basedow's disease at one time in life; at the age of 24 the patient received a shock that seemed to produce a condition of uncertainty and confusion of mind which unfitted her for her work. that of a typewriter and stenographer. For some months she continued to show nervous conditions and mental impairment, at times talked of others having an influence over her and that her thoughts were not her own. She was never truly insane nor so declared, neither was there any necessity for any special restraint; never suicidal or homicidal; some times excited, at others depressed, but never to a very unpleas ant or unreasonable degree; in such a state she continued for a period of about two years. As time went on she showed signs, in various ways, of increasing erotism, delighting in relating her experience with men and her ideas of man and his relations to women, marriage relations, etc., of ten expressing the belief that marriage would be a cure for her; physically she presented no marked myxedematous appearance. at jeast there were no well.defined symptoms of my xedema; there was a strong tendency to increase weight, face was lardaceous and pasty, hands somewhat clubbed and finger strutted, skin greasy. Thyroid was given in increasing doses, commencing with 0.32 gram doses, $t$. i. d.; after the fifth day the doses were 0.65 gram three times a day; at the end of four weeks she was taking 4 grams per day, at which time the improvement was so marked in every respect that she was declared well by one of the leading neurologists of the country : the erotism had all disappeared, she was again the modest girl of former days, improved in every direction; yet we looked upon the case with some degree of suspicion, fearing that by the withdrawal of the drug she might have recurrent symptoms; the state of high tension in the circulation had been kept up for a number of woeks, pulse ranging from 90 to 120 a large part of the time, with but little elevation of temperature or other looked-for attendant symptoms while under the thyroid treatment; the urine presented nothing abnormal at any time; some nausea at times and one diarrheal attack during the frst six days; under advice it was thought best to gradually withdraw the thyroid and let the circulation come down to its normal rate. The thyroid being reduced to a minimum amount, $0.32 \mathrm{gram}$ The thyroid being reduced to a minimum amount, 0.32 gram
per day, close observation was kept over the patient and after 
she had been on the minimum amount five days, recurrent symptoms came on; she became disturbed and erratic and a complete relapse followed. After watching the symptoms a few days the thyroid treatment was returned to and given in increasing doses; no apparent change was noticeable until 3 grame per day were given. After the second week the maximum amount of 4 grams daily was given. Decided improvement followed and after being on the full doses one week and a half she showed none of her unnatural symptoms or feelings; in both instances the improvement under the thyroid treatment has been striking and progressive. There can be no doubt as to the cause of the change. We now believe it will be necessary to continue the thyroid treatment for an indefinite time and that her thyroids are defective in supplying a needed element.

While we have not seen such changes as Dr. Clauston of Edinburgh, Dr. C. K. Clark of Kingston, Ont., Dr. Chas. G. Hill of Mt. Hope Retreat, Baltimore, we do believe the thyroid should be tried even though myxedematous appearances are not apparent. DISCUSSION.

Dr. Canfield-My experience with hyoscin in insomnia and melancholia has been very unsatisfactory and I have recently given it a very thorough trial. In one case, the insomnia seemed to vary more than with the dose of trional which I had advised, finding at the beginning that hyoscin was not powerful enough in itself to give any satisfactory sleep. I have found in some other cases that it is more uncertain than almost anything I know of as a hypnotic. Has Dr. Watson found any kind of diet efficient in these cases? I could get no satisfactory results along these lines.

Dr. WATson--I have not found any line of diet that is worth mentioning as being reliable.

Dr. C. H. Hughes--When hyoscyamus was first introduced into practice Merck sent me the amorphous hyoscyamus. I tried it to my entire satiofaction. After leaving the asylum I tried it considerably. I recollect a case that began with acute mania, in which the immediate effect was magical, after the ordinary doses of chloral hydrate had failed. I think the result was to prolong that and other cases. I began the use of hyoscyamus about 1872 . It seemed not to do the case any good except to produce sleep. In a case of maniacal excitement there is nothing like hyoscyamus. In treating melancholia I always give codeia, in doses adequate to make an impression on the patient and change his peychic feelings ; then I withdraw it. It is surprising how small a dose of codeia will suffice in many cases. Less than 0.065 gram is not effective, but 0.13 gram of codeia combined with aloin given three times or twice a day, after the morning and midday meals, is generally sufficient.

Dr. KINDRED I would favor hyoscin in preference to the other related alkaloid. I have found, as a point of difference in the histologic action of the two, that while hyoscyamus gives a most distinct action as a motor sedative, it does not cause sleep so surely as hyoscin. Hyoscin, in my experience, has acted much more happily than in that of Dr. Canfield. I usually expect to secure from six to eight hours' sleep from a full dose, which I would call $1 / 50$ grain $(0.0015$ gram) usually, or, if there be any idiosyncrasy or any danger from giving so much, a dose of $1 / 100$ grain ( $0.0007 \mathrm{gram})$. With regard to diet in melancholia, I would refer to the method employed by Professor Clauston, which he calls over-feeding. It is only a system of filling the economy with albuminous material. $\mathrm{He}$ uses pure milk and egg, sometimes combined with vegetable food in the form of liquid extract. He gives from a pint to a quart of this albuminous mixture, every three or four hours. That, I believe, has the advantage which he claims of building up the nutrition as rapidly as possible, as is necessary in melancholia, which is the result of mal-nutrition. But it has the further advantage of leaving as little residuum and debris in the intestinal canal as possible. Since, as Dr. Watson claims, this condition may even result from auto-intoxication, that is an important point in treating melancholia.

In reply to a query Dr. Hughes stated that he did not use hyoscin to the exclusion of chloral hydrate or some form of bromid, preferably bromid of sodium. He would not rely on hyoscin except as a pure hypnotic to coerce sleep in cases in which the necessity for bringing about sleep immediately is imperative. He did not use hyoscyamus at all.

Dr. WATson .... In regard to the use of bromid of sodium in such doses as 4 grams or more, I very frequently find that my patient seems to be more depressed afterward, while the less frequent doses of hyoscin seem to have a less disastrous effect. Bromid in combination with strong bitter tonics may sometimes be safely used.

\section{RUMINATION IN MAN.}

Presented to the Section on Neurology and Medical Jurisprudence, at the Forty-eighth Annual Meeting of the American Medical Association, at Philadelphia, Pa., June, 1-4, 1897.

\section{BY WHARTON SINKLER, M.D.}

PHILADEIPHIA. PA.

Merycism, or rumination in man, although described by ancient medical writers, has attracted but little attention until within the past few years. Hammond, who reported a case in 1894 , said that only about fifty cases had been recorded up to that time. Since then, however, a number of additional cases have been recorded, both in this country and abroad. I have however been able to find only thirteen reported in America, but in Europe a great number of cases have been added to the literature in recent years. The American cases are:

Hubbard: Medical Record, 1886, p. 122, one case.

Max Einhorn : Medical Record, 1890, p. 38, two cases.

Charles Shattinger : Medical Fortnightly, 1892, p. 163, one case.

W. A. Hammond: Proceedings of American Neurological Association, 1894, one case.

D. W. Graham: Chicago Medical Examiner, 1894, Vol. xv, p. 118 , one case.

Edward Runge: St. Louis Med. Review, 1894, p. 121, one case.

Edward Runge: Boston Med. and Surg. Journal, 1895, Vol. Cxxxis, p. 575, three cases.

Albert Abrahams: Medical News, 1895 , p. 405, one case.

David Riesman : Journ. of Nervous and Mental Diseases. 1895, two cases.

It is probable that a great number of mericoles exist whose cases have not been reported, being regarded by their physicians as cases of ordinary indigestion with vomiting. It is also likely that many persons who have the habit of regurgitation of their food are withheld from saying anything about it, either because they do not think it worth while to consult a physician, or because they are ashamed to speak of it. Brown. Séquard and Blanchard were mericoles, and the latter has written a treatise on rumination.

The disorder was described very fully by the great Italian anatomist, Fabricius ab Aquapendente, in 1687. He seems, however, to have been somewhat tainted with superstition in regard to the subject, for he describes two cases of merycismus, one of which was a nobleman alleged to have two horns on his forehead, and the other was a monk whose father had a little horn on the forehead (Lemoin and Linossier, Rev. de Med., 1844, p. 177). Pipelet wrote the first really scientific paper on the subject, in 1786.

Rumination or merycism must not be regarded as the simple regurgitation or vomiting of food. It is a return of the food shortly after it has been swallowed, unattended by nausea, retching or disgust. In many cases only the portions of food which need remastication are returned. The regurgitated food is either rejected from the mouth, or it is remasticated and again swallowed. The act of rumination in man is analogous to the process of rumination or chewing the cud in certain of the lower animals. This act in the herbivorous animal is probably the result of evolution. Blanchard (on rumination, "Handbook of the Medical Sciences," Vol. vIII) says that "the habit of rumination was acquired by certain animals at the time that the carnivora first appeared upon the earth. Fearful of attack, the ruminants grazed rapidly, ready for flight at the first intimation of danger; then, having reached a place of safety, their food was regurgitated and masticated thoroughly." "A similar condition" 